Research Article

\title{
Incidence, Outcomes, and Factors Associated with Intra-Abdominal Hypertension and Primary Abdominal Compartment Syndrome in Abdominopelvic Injury Patients
}

\author{
Amonpon Kanlerd ${ }^{D},{ }^{1}$ Krissada Nakornchai, ${ }^{1}$ Karikarn Auksornchart, ${ }^{1}$ \\ and Warapan Watkwaw \\ ${ }^{1}$ Unit of Trauma and Surgical Critical Care, Division of General Surgery, Department of Surgery, Faculty of Medicine, \\ Thammasat University, Bangkok, Thailand \\ ${ }^{2}$ Registered Nurse, Surgical Intensive Care Units, Thammasat University Hospital, Khlong Nueng, Thailand
}

Correspondence should be addressed to Amonpon Kanlerd; amonponk@hotmail.com

Received 7 March 2020; Revised 2 June 2020; Accepted 29 July 2020; Published 17 August 2020

Academic Editor: Enrico Camporesi

Copyright $\odot 2020$ Amonpon Kanlerd et al. This is an open access article distributed under the Creative Commons Attribution License, which permits unrestricted use, distribution, and reproduction in any medium, provided the original work is properly cited.

\begin{abstract}
Background. The primary aim was to identify the incidence of intra-abdominal hypertension (IAH) and primary abdominal compartment syndrome ( $\left.1^{\circ} \mathrm{ACS}\right)$ of abdominopelvic injury patients at Thammasat University Hospital (TUH), Thailand, and the secondary objective was to evaluate those factors that contributed to developing these conditions. Methods. The retrospective cohort of 38 abdominopelvic injury cases was admitted to the intensive care unit at Thammasat University Hospital, from January $1^{\text {st }}$ to December $31^{\text {st }}, 2018$. The bladder pressure was recorded every 4 hours until the urethral catheter was removed. Data of age, gender, weight, height, body mass index, injury mechanisms, initial vital signs, imaging, laboratory data, blood component requirements, abdominal organs involved, treatments including surgery and intervention radiology, abbreviated injury scale (AIS) and injury severity score (ISS), length of ICU stays, and results of treatment were all analyzed. Results. The patients were mostly young (mean age 31.5 years), male (68.4\%), and suffering from blunt trauma $(89.5 \%)$. The mean maximum bladder pressure was $8.3 \pm 5.2 \mathrm{mmHg}$. Six patients $(15.8 \%)$ developed IAH, and one patient $(2.6 \%)$ was diagnosed with $1^{\circ}$ ACS. Two patients expired. The multivariate analysis showed the patient who had initial $\mathrm{Cr} \geq 1.5 \mathrm{~g} / \mathrm{dL}$, lower extremity including pelvis AIS $\geq 3$, and ISS $>15$ was significantly associated with the developing of IAH. Conclusions. The incidence of IAH and $1^{\circ}$ ACS was $15.8 \%$ and $2.6 \%$. Predicted factors to find developing IAH were initial $\mathrm{Cr} \geq 1.5 \mathrm{~g} / \mathrm{dL}$, lower extremity AIS $\geq 3$, and ISS $>15$. We should consider awareness of IAH and $1^{\circ} \mathrm{ACS}$ in abdominopelvic injury patients.
\end{abstract}

\section{Introduction}

Intra-abdominal hypertension (IAH) is defined as a sustained elevated level of intra-abdominal pressure (IAP) more than $12 \mathrm{mmHg}$. Abdominal compartment syndrome (ACS) is defined as a sustained raised level of IAP more than $20 \mathrm{mmHg}$ with or without abdominal perfusion pressure (APP) less than $60 \mathrm{mmHg}$ and developing of new end-organ failure. Primary ACS $\left(1^{\circ} \mathrm{ACS}\right)$ is defined as ACS developing from intra-abdominal pathologies. Secondary ACS $\left(2^{\circ}\right.$ ACS $)$ means ACS following from extra-abdominal pathologies.
And recurrent ACS is defined as redeveloped ACS following medical or surgical treatments of $1^{\circ}$ or $2^{\circ}$ ACS [1].

ACS is caused by persistent increase in IAP leading to a decrease in venous return and cardiac output, and then, endorgan damage occurs [2]. Many reports define both IAH and ACS as significantly associated with morbidity and mortality in critically ill patients [3-5]. The incidence of IAH and ACS varies by the population group; the overall incidence is $30-70 \%$ and $10-35 \%$, respectively [6]. If focusing on a trauma patient group, the incidence of IAH is $2-50 \%$, and the incidence of ACS is $0.6-36 \%$ [7]. 
The indirect intra-abdominal pressure measurement uses a catheter inserted into the intraluminal cavity of an intra-abdominal organ and measures the intraluminal pressure [8]. Nowadays, intravesicular pressure measurement has become the gold standard in the analysis of IAP; it has shown strong correlations to the direct IAP measurement and is reliable $[2,9]$. The standard recommendations to evaluate IAP mostly use the World Society of the Abdominal Compartment Syndrome (WSACS) recommendation 2013. They recommend measuring IAP at least every 4 hours in an injured patient with any known risk factors for IAH/ACS [1].

This study focuses on IAH and $1^{\circ}$ ACS from abdominopelvic injury etiology. We want to know precisely the incidence of these conditions in our institute and which factors contribute to development of IAH $/ 1^{\circ} \mathrm{ACS}$ and also what is the clinical result of these conditions. These data may represent the incidence in specific population and guide us to improve the accuracy of protocol.

\section{Materials and Methods}

This retrospective cohort study was conducted at Thammasat University Hospital (TUH), Pathumthani, a tertiary care center located in the central region of Thailand. The study protocol was approved by the Human Ethics Committee of Thammasat University No. 1 (Faculty of Medicine), Thailand, which also waived the requirement for informed consent due to the retrospective nature of the study.

All adult abdominopelvic injury patients (age $\geq 18$ years old) admitted to the intensive care unit (ICU) from January $1^{\text {st }}$ to December $31^{\text {st }}, 2018$, were included. The exclusion criteria were the patient who could not insert a urethral catheter for any reason and the patient who had a history of pelvic mass bringing compression to the bladder or previous bladder surgery. Data regarding age, gender, weight, height, body mass index (BMI), injury mechanisms, initial vital signs, clinical presentations, imaging, laboratory data, blood component requirements in the first 24 hours, abdominal organs involved, all recorded intravesicular pressure, urethral catheter complications, treatments including surgery and intervention radiology, regional abbreviated injury scale (AIS), injury severity score (ISS), length of ICU stays, and results of treatment (death or alive until discharged) were all collected and analyzed.

Abdominopelvic injury is defined as any injury to internal organ of abdomen and abdominal wall. The boundary of the abdominopelvic region is below the diaphragm to the pelvic outlet. The injury includes intraperitoneal organs, extraperitoneal organs, pelvic bone, or pelvic viscera. The patient may or may not have had any combined injuries.

All of the patients were initially evaluated at the emergency room (ER) and fitted with a urethral catheter to evaluate the initial intravesicular pressure. The patient who had indication for immediate surgery needed to proceed to the operating room (OR). If the patient did not have indication for surgery, the patient was admitted to ICU for nonoperative management and to intermittent measurement and recording of intravesicular pressure in $\mathrm{mmHg}$ every 4 hours. The measurement of IAP is defined by first emptying the bladder and then filling by a maximum of $25 \mathrm{ml}$ of sterile saline solution via the catheter. The zero is referenced at the midaxillary line, and then, the catheter is held vertically above the patient. The end-expiration fluid level was measured in $\mathrm{cmH}_{2} \mathrm{O}$ and converted to $\mathrm{mmHg}$ by using this formula: $1 \mathrm{mmHg}=1 \mathrm{cmH}_{2} \mathrm{O} \times 0.735$. The patient who had intravesicular pressure more than $12 \mathrm{mmHg}$ was treated by turning the patient into a supine position and then giving adequate pain control medication. We optimized the organ perfusion and avoided excessive fluid resuscitation. If intravesicular pressure was more than $20 \mathrm{mmHg}$, we defined the patient as IAH grade III and considered evaluating endorgan failure for diagnosis of $1^{\circ} \mathrm{ACS}$. The patients diagnosed with $1^{\circ} \mathrm{ACS}$ were treated with decompressive laparotomy.

The primary end point of this study was the patient had abdominopelvic operation which was the end of $1^{\circ} \mathrm{ACS}$ definition, or the urethral catheter was removed. The secondary end point was the length of ICU stays, total blood components required, total operations required, the need for intervention radiology, and mortality.

The statistical analysis tools used were IBM $^{\circledR}$ and SPSS ${ }^{\circledR}$, Version 20 for $\mathrm{Mac}^{\circledR}$ (SPSS, Chicago, Illinois, USA). Values were reported as percentages for categorical variables and mean (range) or mean with standard deviation (SD) for continuous variables. Comparison data, such as demographic and clinical characteristics, were evaluated using bivariable analysis. Correlation analysis of qualitative variables to developing IAH $/ 1^{\circ} \mathrm{ACS}$ was using the Pearson Chisquare test and unpaired $t$-test for quantitative variables. Independent risk factors associated with developing IAH/ $1^{\circ}$ ACS were measured using a stepwise logistic regression method. Statistical significance was set at $p<0.050$.

\section{Results}

A total of 38 consecutive abdominopelvic injury cases were identified in the one year. The mean age was 31.5 years (18-67). Most of the patients were male (68.4\%). Thirty-four patients $(89.5 \%)$ were suffering from a blunt mechanism. The mean patient weight, height, and BMI were $61.2 \pm 11.3 \mathrm{~kg}, 1.67 \pm 0.09 \mathrm{~m}$, and $21.7 \pm 2.8 \mathrm{~kg} / \mathrm{m}^{2}$, respectively. On primary surveys, seven patients $(18.4 \%)$ had airway problems. Six cases $(15.8 \%)$ had ventilation problems, and ten patients $(26.3 \%)$ were suffering from hemorrhagic shock. Three patients (7.9\%) had a Glasgow Coma Scale (GCS) less than 13, and only one patient (2.6\%) developed hypothermia. Secondary surveys showed 17 cases $(44.7 \%)$ had abdominal distension. Three patients (7.9\%) developed generalized peritonitis. Nine cases $(23.7 \%)$ had abdominal wounds, and 2 of them (5.3\%) had internal organ evisceration. Initial mean arterial pressure (MAP) was $88 \pm 16 \mathrm{mmHg}$. Initial pulse rate $(\mathrm{PR})$ was $101 \pm 18 \mathrm{bpm}$. Twenty-eight cases $(73.7 \%)$ had normal chest film. Sixteen patients $(42.1 \%)$ were positive focused assessment sonography in trauma (FAST). Twenty-eight cases $(73.7 \%)$ proceeded to computed tomography (CT) of the abdomen, and 26 cases $(68.4 \%)$ had positive results. Six patients $(15.8 \%)$ presented with gross hematuria. Most of the patients $(52.6 \%)$ 
had single abdominopelvic organ injury, and three patients (7.9\%) had four-organ injuries. Four patients (10.5\%) had a pelvic fracture. Three patients $(7.9 \%)$ had urinary bladder injury, but no one had a ruptured bladder. The mean initial IAP was $7.6 \pm 4.5 \mathrm{mmHg}$. The initial hemoglobin $(\mathrm{Hb})$ level was $12.8 \mathrm{~g} / \mathrm{dL}(8.3-16.3)$, and the platelets count was 248,579 cells/cu.mm $(146,000-378,000)$. The initial creatinine level (Cr) was $1.09 \pm 0.34 \mathrm{~g} / \mathrm{dL}$, and serum bicarbonate level $\left(\mathrm{HCO}_{3}\right)$ was $21.02 \pm 3.79 \mathrm{mmol} / \mathrm{L}$. The international normalized ratio (INR) was $1.11 \pm 0.15$. Most of the cases (52.6\%) had minor head AIS, and $65.8 \%$ had minor chest AIS. For abdominal including pelvic AIS, 6 cases $(15.8 \%)$ had minor injury, 11 cases (28.9\%) had moderate injury, 10 cases had serious injury, 10 cases had severe injury, and only 1 case (2.6\%) was a critical injury. For lower extremity included pelvic girdle AIS, 24 cases $(63.2 \%)$ had minor injury, 8 cases (21.1\%) had moderate injury, 4 cases $(10.5 \%)$ had serious injury, and 2 cases (5.3\%) had severe injury. The mean ISS was $19 \pm 11$. The demographic data and patient characteristics are listed in Table 1.

Six cases $(15.8 \%)$ developed IAP $\geq 12 \mathrm{mmHg}$ and were defined as the IAH group. Only one patient $(2.6 \%)$ from the IAH grade III group developed renal failure after admission and was defined as $1^{\circ}$ ACS. Seventeen cases (43.7\%) required the operative treatment; 11 cases $(28.9 \%)$ needed abdominal operations, and 5 patients (13.2\%) required orthopedic surgeries (included pelvic bone fixation). Six patients $(15.8 \%)$ required the angiography with embolization. There were no complications of urethral catheterized and IAP measurement in this study. The mean ICU stay was $4.5 \pm 3.3$ days. The mean of blood components required in the first 24 hours was $1.2 \pm 1.1$ unit of packed red cells (PRC), $0.7 \pm 1.4$ unit of fresh frozen plasma (FFP), and $0.5 \pm 1.5$ unit of platelets concentration. Two patients (5.3\%) died: one from a severe head injury, and the other was multiorgan failure syndrome. The result of treatments is listed in Table 2.

The incidence of IAH and $1^{\circ}$ ACS from this study was $15.8 \%$ and $2.6 \%$, respectively. One patient from the IAH grade III group was diagnosed with blunt abdominal injury and lateral compression-type pelvic fracture. The patient had hemodynamic stability on admission (WSES grade II) and received pelvic angiography with embolization as a primary treatment. The patient subsequently developed oliguria concomitant with gradually increased IAP and serum creatinine in the first day of ICU admission. The maximum IAP was $23 \mathrm{mmHg}$. The patient was diagnosed with $1^{\circ} \mathrm{ACS}$ and proceeded to decompressive celiotomy. The operative finding was $200 \mathrm{ml}$ of hemoperitoneum, a serosal tear of the transverse colon, and a large zone III retroperitoneal hematoma with a fractured pelvis. Preperitoneal packing with primary repair of the colon was conducted, and then, temporary abdominal closure with negative pressure wound therapy and external pelvic fixation was performed. Unfortunately, the patient expired after this operation with multiorgan failure syndrome. IAH and $1^{\circ}$ ACS cases are listed in Table 3.

Many variables had a significant difference between the patient who developed IAH and not as shown in Table 1. Some of the variables were selected for a statistical calculation for which factors are associated with developing IAH. The multivariate analysis with stepwise regression analysis was performed, and we found the patient who had initial $\mathrm{Cr} \geq 1.5 \mathrm{~g} / \mathrm{dL}$, lower extremity including pelvis AIS $\geq 3$, and ISS $>15$ were statistically significantly associated with developing IAH at $p<0.050$. The relative risk (RR), $95 \%$ confidence interval $(95 \% \mathrm{CI})$, and the result of multivariate analysis are listed in Table 4 . We failed to demonstrate which factors are associated with developing $1^{\circ} \mathrm{ACS}$ because only 1 case developed this condition.

\section{Discussion}

The incidence of IAH in our study was $15.8 \%$ ( 6 cases/year). In past studies $[7,10]$, the incidence of IAH in mixed trauma populations was $2-50 \%$. Balogh et al. [11] reported the incidence of IAP $>12 \mathrm{mmHg}$ shock/trauma cases who were admitted to ICU was $75 \%$. A study focusing on pelvic fracture patients [12] reported the incidence of IAH was $9.7 \%$. The data of the IAH incidence in our study focus only on abdominopelvic injury patients who were admitted to ICU. This finding of this is more concise coming from a unique population.

Some studies have reported the prevalence and incidence of ACS in trauma patients. One study [13] said the rate of ACS in severe trauma patients was $0-28 \%$, and subgroup analysis in trauma patients admitted to ICU and patients who had visceral injury was $0-5.3 \%$ and $1-20 \%$, respectively. Ivatury et al. [14] reported $32 \%$ incidence of ACS in severe abdominal trauma, and Balogh et al. [15] reported the incidence of $1^{\circ} \mathrm{ACS}$ in major torso trauma who required shock resuscitation was $6 \%$. Compared to our result, the incidence of $1^{\circ} \mathrm{ACS}$ is $2.6 \%$. The result is different from previous data because of the difference in ACS definitions. In our study, we defined $1^{\circ}$ ACS as the sustained increase IAP $>20 \mathrm{mmHg}$ with new organ dysfunction/failure developing from abdominopelvic injury, but Ivatury et al. [14] defined ACS as a clinical syndrome characterized by increased intra-abdominal pressure (IAP $>25 \mathrm{cmH}_{2} \mathrm{O}$ ) and improvement after abdominal decompression, and they included all type of ACS. Balogh et al. [15] defined $1^{\circ}$ ACS as the patient having intraperitoneal injuries with IAP $>25 \mathrm{mmHg}$ and progressive organ dysfunction despite resuscitation, which improved after decompression. The true incidence of $1^{\circ} \mathrm{ACS}$ in abdominopelvic injury is still not established although this study may be the first report in this specific population and using the exact $1^{\circ}$ ACS definitions according WSACS recommendations 2013 [1].

The multivariate analysis shows initial $\mathrm{Cr} \geq 1.5 \mathrm{~g} / \mathrm{dL}$, lower extremity including pelvis AIS $\geq 3$, and ISS $>15$ can predict the development of IAH in this study. Many investigators have identified factors contributing to the development of IAH. In the latest prospective multicenter study in mixed critically ill patients with IAH [16], they found BMI $\geq 27 \mathrm{~kg} / \mathrm{m}^{2}$, APACHE II $\geq 18$ points, abdominal distension, and absence of bowel sounds, and PEEP $\geq 7 \mathrm{cmH}_{2} \mathrm{O}$ was associated with IAH. Mahmood et al. [17] found increased base deficit level, and frequent blood transfusion could predict the developing IAP $>20 \mathrm{mmHg}$. He L et al. [12] 
TABle 1: Patient characteristics.

\begin{tabular}{|c|c|c|c|c|}
\hline Characteristics & Total $(N=38)$ & Non-IAH $(N=32)$ & IAH $(N=6)$ & $p$ \\
\hline \multicolumn{5}{|l|}{ Demographic } \\
\hline $\operatorname{Sex}(\mathrm{M}: \mathrm{F}, n)$ & $26: 12$ & $23: 3$ & $3: 3$ & 0.290 \\
\hline Age (mean with SD, years) & $31.5 \pm 12.7$ & $31.4 \pm 12.1$ & $32.0 \pm 12.0$ & 0.920 \\
\hline Weight (mean with SD, kg) & $61.2 \pm 11.3$ & $61.3 \pm 12.0$ & $60.5 \pm 8.1$ & 0.879 \\
\hline Height (mean with SD, m) & $1.67 \pm 0.09$ & $1.67 \pm 0.09$ & $1.68 \pm 0.08$ & 0.909 \\
\hline BMI (mean with SD, $\mathrm{kg} / \mathrm{m}^{2}$ ) & $21.7 \pm 2.8$ & $21.8 \pm 3.0$ & $21.5 \pm 1.8$ & 0.798 \\
\hline \multicolumn{5}{|l|}{ Mechanism of injury } \\
\hline Blunt: penetrating $(n)$ & $34: 4$ & $29: 3$ & $5: 1$ & 0.593 \\
\hline $\operatorname{MVC}(n(\%))$ & $29(76.3)$ & $25(78.1)$ & $4(66.7)$ & 0.545 \\
\hline Fall from the height $(n(\%))$ & $3(7.9)$ & $2(6.3)$ & $1(16.7)$ & 0.385 \\
\hline Body assault $(n(\%))$ & $3(7.9)$ & $3(9.4)$ & $0(0)$ & 0.435 \\
\hline \multicolumn{5}{|l|}{ Primary survey } \\
\hline Airway compromised (n (\%)) & $7(18.4)$ & $5(15.6)$ & $2(33.3)$ & 0.305 \\
\hline $\begin{array}{l}\text { Breathing and ventilation } \\
\text { problem }(n(\%))\end{array}$ & $6(15.6)$ & $5(15.6)$ & $1(16.7)$ & 0.949 \\
\hline Hemorrhagic shock $(n(\%))$ & $10(26.3)$ & $6(18.8)$ & $4(66.7)$ & 0.014 \\
\hline $\mathrm{GCS}<13(n(\%))$ & $3(7.9)$ & $3(9.4)$ & $0(0)$ & 0.435 \\
\hline Hypothermia $(n(\%))$ & $1(2.6)$ & $0(0)$ & $1(16.7)$ & 0.019 \\
\hline \multicolumn{5}{|l|}{ Initial vital signs } \\
\hline SBP (mean with SD, mmHg) & $116 \pm 19$ & $118 \pm 16$ & $104 \pm 29$ & 0.104 \\
\hline DBP (mean with SD, mmHg) & $74 \pm 15$ & $76 \pm 13$ & $64 \pm 21$ & 0.080 \\
\hline MAP (mean with SD, mmHg) & $88 \pm 16$ & $90 \pm 13$ & $77 \pm 24$ & 0.076 \\
\hline PR (mean with SD, bpm) & $101 \pm 18$ & $99 \pm 18$ & $113 \pm 15$ & 0.073 \\
\hline $\mathrm{RR}$ (mean with $\mathrm{SD}, / \mathrm{min}$ ) & $21 \pm 4$ & $21 \pm 4$ & $23 \pm 4$ & 0.231 \\
\hline BT (mean with SD, ${ }^{\circ} \mathrm{C}$ ) & $36.9 \pm 0.8$ & $36.9 \pm 0.8$ & $36.6 \pm 1.1$ & 0.437 \\
\hline \multicolumn{5}{|l|}{ Abdominal signs } \\
\hline Abdominal tenderness $(n(\%))$ & $19(50)$ & $15(46.9)$ & $4(66.7)$ & 0.374 \\
\hline Peritonitis $(n(\%))$ & $3(7.9)$ & $2(6.3)$ & $1(16.7)$ & 0.385 \\
\hline Abdominal distention $(n(\%))$ & $17(44.7)$ & $11(34.3)$ & $6(100)$ & 0.003 \\
\hline Abdominal wounds $(n(\%))$ & $9(23.7)$ & $7(21.9)$ & $2(33.3)$ & 0.545 \\
\hline Flank and back injury $(n(\%))$ & $3(7.9)$ & $3(9.4)$ & $0(0)$ & 0.435 \\
\hline Organ evisceration $(n(\%))$ & $2(5.3)$ & $1(3.1)$ & $1(16.7)$ & 0.173 \\
\hline \multicolumn{5}{|l|}{ Initial imaging } \\
\hline Pelvis fracture $(n(\%))$ & $4(10.5)$ & $2(6.3)$ & $2(33.3)$ & 0.047 \\
\hline Positive FAST $(n(\%))$ & $16(42.1)$ & $12(37.5)$ & $4(66.7)$ & 0.184 \\
\hline Positive abdominal CT $(n(\%))^{*}$ & $26(68.4)$ & $22(68.7)$ & $4(66.7)$ & 0.549 \\
\hline \multicolumn{5}{|l|}{ Initial laboratory } \\
\hline \multicolumn{5}{|l|}{ Urine analysis } \\
\hline Microscopic hematuria $(n(\%))$ & $16(42.1)$ & $13(40.6)$ & $3(50)$ & 0.887 \\
\hline Gross hematuria $(n(\%))$ & $6(15.8)$ & $5(15.6)$ & $1(16.7)$ & \\
\hline Hct (mean with SD, gm\%) & $38.9 \pm 6.1$ & $39.4 \pm 6.3$ & $36.4 \pm 4.6$ & 0.271 \\
\hline $\mathrm{Hb}$ (mean with SD, g/dL) & $12.9 \pm 1.8$ & $13.1 \pm 1.8$ & $11.8 \pm 1.6$ & 0.115 \\
\hline $\begin{array}{l}\text { Platelets count (mean with SD, } \\
\times 10^{3} \text { cells } / \text { cu.mm) }\end{array}$ & $249 \pm 61$ & $249 \pm 60$ & $247 \pm 74$ & 0.946 \\
\hline INR (mean with SD) $)^{\dagger}$ & $1.1 \pm 0.2$ & $1.1 \pm 0.1$ & $1.3 \pm 0.2$ & 0.007 \\
\hline Creatinine (mean with SD, g/dL) & $1.1 \pm 0.3$ & $1.0 \pm 0.3$ & $1.5 \pm 0.2$ & 0.001 \\
\hline $\begin{array}{l}\text { Bicarbonate (mean with SD, } \\
\mathrm{mmol} / \mathrm{L} \text { ) }\end{array}$ & $21.0 \pm 3.8$ & $21.8 \pm 3.4$ & $17.0 \pm 3.1$ & 0.003 \\
\hline $\begin{array}{l}\text { Base excess (mean with SD, mEq/ } \\
\mathrm{L})^{\ddagger}\end{array}$ & $-7.3 \pm 8.3$ & $-4.2 \pm 7.6$ & $-11.0 \pm 8.1$ & 0.146 \\
\hline Lactate (mean with $\mathrm{SD}, \mathrm{mmol} / \mathrm{L})^{\ddagger}$ & $5.7 \pm 4.9$ & $4.2 \pm 3.8$ & $7.6 \pm 5.7$ & 0.225 \\
\hline \multicolumn{5}{|l|}{ Abdominopelvic organ injury } \\
\hline Diaphragm $(n(\%))$ & $1(2.6)$ & $1(3.1)$ & $0(0)$ & 0.661 \\
\hline Liver $(n(\%))$ & $19(50)$ & $14(43.8)$ & $5(83.3)$ & 0.075 \\
\hline Spleen $(n(\%))$ & $5(13.2)$ & $3(9.4)$ & $2(33.3)$ & 0.111 \\
\hline Kidney $(n(\%))$ & $13(34.2)$ & $11(34.3)$ & $2(33.3)$ & 0.961 \\
\hline Pancreas $(n(\%))$ & $1(2.6)$ & $0(0)$ & $1(16.7)$ & 0.019 \\
\hline Adrenal $(n(\%))$ & $1(2.6)$ & $1(3.1)$ & $0(0)$ & 0.661 \\
\hline Small bowel $(n(\%))$ & $3(7.9)$ & $2(6.3)$ & $1(16.7)$ & 0.385 \\
\hline
\end{tabular}


TABLE 1: Continued.

\begin{tabular}{|c|c|c|c|c|}
\hline Characteristics & Total $(N=38)$ & Non-IAH $(N=32)$ & IAH $(N=6)$ & $p$ \\
\hline Colon $(n(\%))$ & $3(7.9)$ & $1(3.1)$ & $2(33.3)$ & 0.012 \\
\hline Mesentery $(n(\%))$ & $5(13.2)$ & $2(6.3)$ & $3(50)$ & 0.004 \\
\hline Bladder $(n(\%))$ & $3(7.9)$ & $3(9.4)$ & $0(0)$ & 0.435 \\
\hline Internal iliac vessel $(n(\%))$ & $1(2.6)$ & $1(3.1)$ & $0(0)$ & 0.661 \\
\hline Abdominal wall $(n(\%))$ & $8(21.1)$ & $7(21.9)$ & $1(16.7)$ & 0.774 \\
\hline Multiple organ injury $(n(\%))$ & $18(47.4)$ & $13(40.6)$ & $5(83.3)$ & 0.055 \\
\hline \multicolumn{5}{|l|}{ Abbreviated injury scale (AIS) } \\
\hline Head AIS $(3: 4: 5, n)$ & $9: 0: 1$ & $8: 0: 0$ & $1: 0: 1$ & 0.090 \\
\hline Face AIS $(3: 4: 5, n)$ & $0: 0: 1$ & $0: 0: 0$ & $0: 0: 1$ & 0.057 \\
\hline $\begin{array}{l}\text { Chest AIS } \\
(3: 4: 5, n)\end{array}$ & $8: 2: 0$ & $7: 2: 0$ & $1: 0: 0$ & 0.721 \\
\hline Abdominopelvic AIS $(3: 4: 5, n)$ & $10: 10: 1$ & $8: 7: 0$ & $2: 3: 1$ & 0.038 \\
\hline $\begin{array}{l}\text { Lower extremity and pelvis AIS } \\
(3: 4: 5, n)\end{array}$ & $4: 2: 0$ & $2: 0: 0$ & $2: 2: 0$ & 0.001 \\
\hline $\begin{array}{l}\text { Injury severity scores (ISS) (mean } \\
\text { with SD) }\end{array}$ & $19 \pm 11$ & $16 \pm 7$ & $35 \pm 17$ & $<0.001$ \\
\hline
\end{tabular}

${ }^{*}$ Ten patients (26.8\%) did not proceed to abdominal CT scan; ${ }^{\dagger}$ six patients (15.8\%) did not have initial INR result; ${ }^{*}$ thirteen cases (39.5\%) had initial base excess and lactate data.

TABLE 2: The result of treatments.

\begin{tabular}{|c|c|c|c|c|}
\hline Variables & Total $(N=38)$ & Non-IAH $(N=32)$ & IAH $(N=6)$ & $p$ \\
\hline \multicolumn{5}{|l|}{ IAP result } \\
\hline Initial IAP (mean with $\mathrm{SD}, \mathrm{mmHg}$ ) & $7.6 \pm 4.5$ & $6.2 \pm 2.4$ & $15.3 \pm 5.7$ & $<0.001$ \\
\hline Maximum IAP (mean with SD, mmHg) & $8.3 \pm 5.2$ & $6.4 \pm 2.3$ & $18.5 \pm 4.5$ & $<0.001$ \\
\hline ICU stay (mean with SD, days) & $4.5 \pm 3.3$ & $3.5 \pm 1.2$ & $9.8 \pm 5.7$ & $<0.001$ \\
\hline \multicolumn{5}{|l|}{ Blood components required in 24 hours } \\
\hline PRC (mean with SD, units) & $1.2 \pm 1.1$ & $0.7 \pm 1.1$ & $3.5 \pm 2.3$ & $<0.001$ \\
\hline FFP (mean with SD, units) & $0.7 \pm 1.4$ & $0.4 \pm 1.1$ & $2.3 \pm 2.0$ & 0.001 \\
\hline Platelets concentration (mean with SD, units) & $0.5 \pm 1.5$ & $0.1 \pm 0.7$ & $2.0 \pm 3.3$ & 0.005 \\
\hline \multicolumn{5}{|l|}{ Treatment options } \\
\hline Nonoperative management $(n(\%))$ & $21(55.3)$ & $20(62.5)$ & $1(16.7)$ & 0.038 \\
\hline Operative management $(n(\%))$ & $17(43.7)$ & $12(37.5)$ & $5(83.3)$ & 0.038 \\
\hline Abdominopelvic operations $(n(\%))$ & $11(28.9)$ & $6(18.8)$ & $5(83.3)$ & 0.001 \\
\hline Neurooperations $(n(\%))$ & $2(5.3)$ & $2(6.3)$ & $0(0)$ & 0.529 \\
\hline Chest operations $(n(\%))$ & $2(5.3)$ & $2(6.3)$ & $0(0)$ & 0.529 \\
\hline Orthopedic operations $(n(\%))$ & $5(13.2)$ & $2(6.3)$ & $3(50)$ & 0.004 \\
\hline Intervention radiology $(n(\%))$ & $6(15.8)$ & $3(9.4)$ & $3(50)$ & 0.038 \\
\hline \multicolumn{5}{|l|}{ Results } \\
\hline Alive until discharge $(n(\%))$ & $36(94.7)$ & $31(96.9)$ & $5(83.3)$ & 0.012 \\
\hline Death $(n(\%))$ & $2(5.3)$ & $1(3.1)$ & $1(16.7)$ & 0.173 \\
\hline
\end{tabular}

TABLE 3: Incidence of IAH and $1^{\circ}$ ACS.

\begin{tabular}{lccc}
\hline Group & Definitions $(\mathrm{mmHg})$ & Incidence (cases/year) & \% \\
\hline IAH & IAP $\geq 12$ & 6 & 15.8 \\
Grade I & IAP 12-15 & 2 & 5.3 \\
Grade II & IAP 16-20 & 2 & 5.3 \\
Grade III & IAP 21-25 & 2 & 5.3 \\
Grade IV & IAP $>25$ & 0 & 0 \\
$1^{\circ}$ ACS & IAP $>20$ with new organ dysfunction/failure & 1 & \\
\hline
\end{tabular}

reported only fluid resuscitation over 24 hours was a significant association with IAP $>12 \mathrm{mmHg}$, and each $1 \mathrm{~L}$ increment fluid over 24 hours was significantly associated with an increased $5 \mathrm{mmHg}$ of IAP in fractured pelvis patients. Vatankhah et al. [18] reported risk factors contributed to developing of IAH and ACS in blunt abdominal trauma patients (mixed all age groups). They found the amount of fluid received and pelvis fracture was associated with IAH and ACS but did not evaluate the cut-off point of these factors. From our perspective, we cannot conclude from previous studies which factors contribute to the development of IAH due to variation and mixed population data. This is the strong 
TABLE 4: Relative risk (RR) of significant factors for developing of IAH, univariate analysis, and multivariate analysis result.

\begin{tabular}{lccc}
\hline Variables & RR $(95 \% \mathrm{CI})$ & Univariate $(p)$ & Multivariate $(p)$ \\
\hline Hemorrhagic shock at ER & $5.60(1.21-26.02)$ & 0.014 & 0.982 \\
Initial MAP $\leq 70 \mathrm{mmHg}$ & $0.17(0.05-0.58)$ & 0.012 & 0.728 \\
Initial PR $\geq 100 \mathrm{bpm}$ & $0.28(0.04-2.13)$ & 0.169 & 0.497 \\
Hypothermia at ER & $7.40(3.28-16.72)$ & 0.019 & 0.272 \\
Abdominal distention & $1.55(1.09-2.20)$ & 0.003 & 0.954 \\
Pelvis fracture & $0.24(0.06-0.90)$ & 0.047 & 0.203 \\
Liver injury & $0.20(0.03-1.56)$ & 0.075 & 0.923 \\
Pancreatic injury & $0.14(0.06-0.31)$ & 0.019 & 0.068 \\
Colonic injury & $0.17(0.05-0.58)$ & 0.012 & 0.862 \\
Mesentery injury & $0.15(0.04-0.55)$ & 0.004 & 0.372 \\
Multiple organs injuries & $0.18(0.02-1.40)$ & 0.055 & 0.957 \\
INR $>1.2$ & $0.17(0.04-0.75)$ & 0.009 & 0.595 \\
Cr $\geq 1.5$ g/dL & $0.12(0.04-0.40)$ & 0.001 & $<0.001$ \\
HCO $\leq 18$ mmol/L & $0.23(0.06-0.89)$ & 0.030 & 0.164 \\
Abdominopelvic AIS $\geq 3$ & $1.40(1.07-1.84)$ & 0.016 & 0.369 \\
Lower extremity AIS $\geq 3$ & $0.09(0.02-0.40)$ & $<0.001$ & $<0.001$ \\
ISS $>15$ & $1.30(1.05-1.61)$ & 0.070 & 0.041 \\
\hline
\end{tabular}

point of our study because we focus on a unique population, and we make the cut-off points for parameters. These significant parameters correspond with the severity of injuries that means the patient who suffers from severe abdominopelvic injuries has a high risk to develop IAH. The initial $\mathrm{Cr} \geq 1.5 \mathrm{~g} / \mathrm{dL}$ can occur in severe trauma that may develop after exsanguinating, suboptimal fluid resuscitations, renal injuries, or in case of the patient's preexisting conditions. However, a high level of initial $\mathrm{Cr}$ in this series mostly associates with severely injured cases. This means that our findings may answer the question of which factors contributed to the development of IAH in adult abdominopelvic injury patients.

About the clinical result of IAH, we found statistically significant differences between both groups in the requirement of blood components in first 24 hours, the need for overall procedures, the need for abdominopelvic operations, orthopedic surgeries, the need for intervention radiology, and ICU stays. Many literatures such as Malbrain et al.' study demonstrated poor clinical outcomes followed IAH [4] and found that the patients who developed IAP $>12 \mathrm{mmHg}$ decreased 30-day survival time. Reintam et al. [16] who studied mixed critically ill patients concluded that a higher IAH grade was associated with a higher mortality. Murphy et al. [19] studied mixed ICU patients and found the patients who developed IAH recorded increased ventilation days, vasoactive medication days, ICU length of stay, death in ICU, and death in hospital and also reported IAH was an independent risk factor of ICU mortality (odds ratio 3.33 , 95\% CI 1.46-7.57). We cannot conclude which one is the real clinical result of IAH in abdominopelvic injury patients due to the mixed populations of the previous studies. Our study may answer this question.

\section{Conclusions}

The incidence of IAH and $1^{\circ}$ ACS in our study was $15.8 \%$ and $2.6 \%$, respectively. We found that initial $\mathrm{Cr} \geq 1.5 \mathrm{~g} / \mathrm{dL}$, lower extremity including pelvis AIS $\geq 3$, and ISS $>15$ are the predictors of developing IAH in abdominopelvic injury patients. Further investigation about the actual clinical outcomes of IAH and $1^{\circ} \mathrm{ACS}$ and strengthening of a useful protocol are our next step.

\section{Abbreviations}

IAH: Intra-abdominal hypertension

IAP: Intra-abdominal pressure

APP: Abdominal perfusion pressure

1 $\mathrm{ACS}$ : Primary abdominal compartment syndrome

$2^{\circ}$ ACS: $\quad$ Secondary abdominal compartment syndrome

WSACS: The World Society of the Abdominal Compartment Syndrome

TUH: Thammasat University Hospital

ICU: $\quad$ Intensive care unit

BMI: $\quad$ Body mass index

PRC: $\quad$ Packed red cells

FFP: $\quad$ Fresh frozen plasma

WSES: The World Society of Emergency Surgery

AIS: $\quad$ Abbreviated injury scale

ISS: Injury severity score

ER: The emergency room

OR: The operating room

SD: $\quad$ Standard deviation

MVC: $\quad$ Motor vehicle collision

GCS: Glasgow Coma Scale

SBP: $\quad$ Systolic blood pressure

DBP: Diastolic blood pressure

MAP: $\quad$ Mean arterial pressure

PR: $\quad$ Pulse rate

BT: $\quad$ Body temperature

FAST: $\quad$ Focused assessment sonography in trauma

CT: $\quad$ Computed tomography

$\mathrm{Hb}$ : Hemoglobin

Hct: Hematocrit

Cr: $\quad$ Serum creatinine

$\mathrm{HCO}_{3}$ : $\quad$ Serum bicarbonate

INR: International normalized ratio 
BE: $\quad$ Base excess

RR: $\quad$ Relative risk

APACHE Acute physiologic and chronic health

II: evaluation II

PEEP: $\quad$ Positive end-expiratory pressure.

\section{Data Availability}

The data that support the findings of this study are available from Thammasat University Hospital, but restrictions apply to the availability of these data, which were used under license for the current study and so are not publicly available. Data are however available from the authors upon reasonable request and with permission of the Faculty of Medicine, Thammasat University, and the Thammasat University Hospital.

\section{Ethical Approval}

This project was ethically approved by the Human Ethics Committee of Thammasat University No. 1 (Faculty of Medicine), Thailand (MTU-EC-SU-1-068/60), and waived the requirement for inform consent due to the retrospective nature of the study.

\section{Disclosure}

This research did not receive any specific grant from funding agencies in the public, commercial, or not-for-profit sectors.

\section{Conflicts of Interest}

The authors declare that they have no conflicts of interest.

\section{Authors' Contributions}

KA contributed to literature search, study design, data interpretation, draft writing, critical revision, and final approval of the final version for submitted. NK made contributions to literature search, data collection, data analysis, and interpretation. AK made contributions to draft writing, critical revision, and faculty collaborations. WW made contributions to data collection and data analysis.

\section{Acknowledgments}

The authors wish to thank Norman Mangnall of Faculty of Medicine, Thammasat University (Thailand), for his help in preparing the English manuscript of this paper.

\section{References}

[1] A. W. Kirkpatrick, D. J. Roberts, J. De Waele et al., "Intraabdominal hypertension and the abdominal compartment syndrome: updated consensus definitions and clinical practice guidelines from the World Society of the Abdominal Compartment Syndrome," Intensive Care Medicine, vol. 39, no. 7, pp. 1190-1206, 2013.

[2] W. K. Rogers and L. Garcia, "Intraabdominal hypertension, abdominal compartment syndrome, and the open abdomen," Chest, vol. 153, no. 1, pp. 238-250, 2018.
[3] J. J. De Waele, I. De Laet, A. W. Kirkpatrick, and E. Hoste, "Intra-abdominal hypertension and abdominal compartment syndrome," American Journal of Kidney Diseases, vol. 57, no. 1, pp. 159-169, 2011.

[4] M. L. N. G. Malbrain, D. Chiumello, P. Pelosi et al., "Incidence and prognosis of intraabdominal hypertension in a mixed population of critically ill patients: a multiple-center epidemiological study*." Critical Care Medicine, vol. 33, no. 2, pp. 315-322, 2005.

[5] M. Sadeghi, A. Kiani, K. Sheikhy, K. Taghavi, M. Farrokhpour, and A. Abedini, "Abdominal compartment syndrome in critically ill patients," Open Access Macedonian Journal of Medical Sciences, vol. 7, no. 7, pp. 1097-1102, 2019.

[6] P. Maluso, J. Olson, and B. Sarani, "Abdominal compartment hypertension and abdominal compartment syndrome," Critical Care Clinics, vol. 32, no. 2, pp. 213-222, 2016.

[7] M. L. Cheatham, "Intraabdominal pressure monitoring during fluid resuscitation," Current Opinion in Critical Care, vol. 14, no. 3, pp. 327-333, 2008.

[8] M. Sugrue, J. J. De Waele, B. L. De Keulenaer, D. J. Roberts, and M. L. N. G. Malbrain, "A user's guide to intra-abdominal pressure measurement," Anestezjologia Intensywna Terapia, vol. 47, no. 3, pp. 241-251, 2015.

[9] A. A. Al-Abassi, A. S. Al Saadi, and F. Ahmed, "Is intrabladder pressure measurement a reliable indicator for raised intra-abdominal pressure? a prospective comparative study," BMC Anesthesiology, vol. 18, no. 1, p. 69, 2018.

[10] J. J. De Waele, J. C. Ejike, A. Leppäniemi et al., "Intra-abdominal hypertension and abdominal compartment syndrome in pancreatitis, paediatrics, and trauma," Anestezjologia Intensywna Terapia, vol. 47, no. 3, pp. 219-227, 2015.

[11] Z. J. Balogh, A. Martin, K. P. van Wessem, K. L. King, P. Mackay, and K. Havill, "Mission to eliminate postinjury abdominal compartment syndrome," Archives of Surgery, vol. 146, no. 8, pp. 938-943, 2011.

[12] L. He, C. Yi, Z. Hou, and D. J. Hak, "Intraabdominal hypertension/abdominal compartment syndrome after pelvic fractures: how they occur and what can be done?" Injury, vol. 50, no. 4, pp. 919-925, 2019.

[13] S. G. Strang, E. M. M. Van Lieshout, O. J. F. Van Waes, and M. H. J. Verhofstad, "Prevalence and mortality of abdominal compartment syndrome in severely injured patients," Journal of Trauma and Acute Care Surgery, vol. 81, no. 3, pp. 585-592, 2016.

[14] R. Ivatury, J. Porter, R. Simon, S. Islam, R. John, and W. Stahl, "Intra-abdominal hypertension after life-threatening penetrating abdominal trauma," The Journal of Trauma: Injury, Infection, and Critical Care, vol. 44, no. 6, pp. 1016-1023, 1998.

[15] Z. Balogh, B. A. McKinley, J. B. Holcomb et al., "Both primary and secondary abdominal compartment syndrome can be predicted early and are harbingers of multiple organ failure," The Journal of Trauma: Injury, Infection, and Critical Care, vol. 54, no. 5, pp. 848-861, 2003.

[16] A. Reintam Blaser, A. Regli, B. De Keulenaer et al., "Incidence, risk factors, and outcomes of intra-abdominal hypertension in critically ill patients-a prospective multicenter study (IROI study)," Critical Care Medicine, vol. 47, no. 4, pp. 535-542, 2019.

[17] I. Mahmood, S. Mahmood, A. Parchani et al., "Intra-abdominal hypertension in the current era of modern trauma resuscitation," ANZ Journal of Surgery, vol. 84, no. 3, pp. 166-171, 2014.

[18] S. Vatankhah, R. A. Sheikhi, M. Heidari, and P. Moradimajd, "The relationship between fluid resuscitation and intra- 
abdominal hypertension in patients with blunt abdominal trauma," International Journal of Critical Illness and Injury Science, vol. 8, no. 3, pp. 149-153, 2018.

[19] P. B. Murphy, N. G. Parry, N. Sela, K. Leslie, K. Vogt, and I. Ball, "Intra-abdominal hypertension is more common than previously thought," Critical Care Medicine, vol. 46, no. 6, pp. 958-964, 2018. 